\title{
PEMANFAATAN KELADI HIAS DALAM MENAMBAH PENGHASILAN RUMAH TANGGA
}

\author{
Eka Umi Kalsum ${ }^{*}$, Akman Daulay ${ }^{2}$ \\ 1,2Program Studi Manajemen ,Fakultas Ekonomi, , Universitas Al-Azhar Medan, Jl. Pintu Air IV \\ No.214, Kwala Bekala, Kec. Medan Johor, Kota Medan, Sumatera Utara 20143 \\ *ekaumi1979@gmail.com
}

\begin{abstract}
ABSTRAK. Pengabdian kepada masyarakat ini berdasarkan ketidakpedulian masyarakat terhadap keberadaan tanaman keladi hias yang dianggap tumbuhan liar padahal berpotensi menambah penghasilan rumah tangga apabila dikelola dengan tepat. Tujuan yang ingin dicapai adalah menimbulkan pengetahuan untuk meningkatkan ide kereatif dan inovatif mengenai pemanfaatan keladi hias untuk menambah penghasilan dalam rumah tangga di Desa Tanjung Gunung Kecamatan Sei Bingei Kabupaten Langkat. Metode yang dilakukan dengan cara pemberian penyuluhan. Hasil kegiatan pengabdian kepada masyarakat ini menunjukkah bahwa sebelum dilaksanakan penyuluhan hanya sekitar $40,7 \%$ ibu rumah tangga yang memiliki pengetahuan dalam meningkatkan ide kreatif dan inovatif sedangkan setelah pelaksanaan penyuluhan ibu rumah tangga yang memiliki pengetahuan dalam meningkatkan ide kreatif dan inovatif sebesar $85 \%$. Kesimpulan dalam kegiatan pengabdian masyarakat ini adalah tercapai pengetahuan dalam meningkatkan ide kreatif untuk memanfaatkan tanaman keladi hias dalam menambah penghasilan rumah tangga
\end{abstract}

Kata kunci: Pengetahuan, Kreatif, Inovatif

ABSTRACT. This community service is based on the community's indifference to the existence of ornamental taro plants, considered wild plants even though they can increase household income if appropriately managed. The goal is to generate knowledge to increase creative and innovative ire regarding ornamental taro to increase household income in Tanjung Gunung Village, Sei Bingei District, Langgkat Regency. The method used is by providing counseling. The results of this community service activity showed that before the counseling was carried out, only about $40.7 \%$ of homemakers knew improving creative and innovative ideas. While after the implementation of counseling, homemakers know about increasing creative and innovative ideas by $85 \%$. The conclusion in this community service is the achievement of knowledge in growing creative ideas to utilize ornamental taro plants in increasing household income.

Keywords: Knowledge, Creative, Innovative

\section{PENDAHULUAN}

Dalam agrobisnis nilai tambah (value added) adalah pertambahan nilai suatu produk atau komoditas melalui proses pengolahan, pengangkutan ataupun penyimpanan dalam suatu produksi. Di Indonesia perhatian untuk mengembangkan nilai tambah suatu produk masih kurang serius padahal Indonesia memiliki potensi yang sangat besar (Anonimus, 2012). Keladi hias merupakan salah satu komoditas pertanian yang apabila dikelola dengan baik akan memiliki nilai tambah (value added) sehingga dapat menambah penghasilan dalam rumah tangga.

Sebagian besar masyarakat desa Tanjung Gunung Kecamatan Sei Bingei Kabupaten Langkat masih menganggap keladi hias sebagai tumbuhan liar yang mengganggu (gulma) yang tumbuh di ladang, kebun atau di pinggir jalan, mereka tidak mengetahui bahwa sumber daya hayati ini dapat dimanfaatkan untuk menambah penghasilan rumah tangga. Keladi hias memiliki warna daun yang memesona, warna dominan putih, pink, merah bahkan paduan warna-warni mencolok hasil silangan dari negeri Thailand (Kadir, 2009). Tumbuhan ini memiliki banyak variasi dari bentuk fisik dan daunnya. Secara umum keladi hias ini mempunyai daun seperti tombak atau berbentuk hati, setiap daun ditopang oleh tangkai daun kecil yang lunak, dan memiliki bentuk bunga seperti corong dengan tajuk penyangga benang sari maupun putik yang besar dan menonjol (Kadir dan Triwahyuni, 2006).

Keladi hias termasuk dalam keluarga Araceae yang merupakan keluarga besar tanaman herba 
tahunan yang biasa tumbuh di daerah tropis dan sub tropis, dengan jumlah sekitar 1.500 spesies (Tomasouw, 2006). Iklim di Indonesia memberikan kemudahan bagi tanaman hias ini. Di samping itu ragamnya pun begitu banyak dijumpai di Indonesia, seperti Caladium Aaron, Caladium Blaze, Caladium Polka Green, Caladium Army look, Caladium Bicalour, Caladium Tricalour, caladiun Handsome dan lain sebagainya. Dilihat dari habitatnya, suku ini ada yang hidup terestrial, epifit, dan di air baik mengapung, tenggelam ataupun separuh terendam air (Kurniawan dan Asih, 2013)

Selain mengandung nilai keindahan pada daunnya keladi hias ini juga mengandung nilai ekonomis untuk hiasan di dalam dan di luar ruangan. Karena memiliki nilai ekonomis tumbuhan ini dapat menjadi bisnis yang menjanjikan dengan keuntungan besar walaupun kebutuhan akan tanaman ini merupakan kebutuhan sekunder tetapi telah memasyarakat. Selain hiasan di rumah pribadi, keladi hias ini juga dapat digunakan di perkantoran, pertokoan, hotel, taman dan sebagainya. Banyaknya minat masyarakat akan tanaman keladi hias ini dapat menjadi prospek masa depan bisnis tanaman hias yang potensial jika dapat memanfaatkan ragam tanaman keladi hias yang begitu banyak dengan meningkatkan nilai tambah melalui ilmu pengetahuan, teknologi, dan seni secara tepat.

\section{METODE}

Metode pelaksanaan dalam program pengabdian kepada masyarakat melalui pemberian penyuluhan tentang pemanfaatan tanaman keladi hias dalam menambah penghasilan rumah tangga kepada ibu rumah tangga di Desa Tanjung Gunung Kecamatan Sei Bingei Kabupaten Langkat ini melalui tiga tahapan rapat strategi pelaksanaan, survei lokasi dan persiapan sarana prasarana. Populasi dalam hal ini menyangkut ibu rumah tangga yang ada di Desa Tanjung Gunung Kecamatan Sei Bingei Kabupaten Langkat, sedangkan sampelnya adalah ibu rumah tangga di Desa Tanjung Gunung Kecamatan Sei Bingei Kabupaten Langkat yang tidak memiliki pekerjaan.

\section{HASIL DAN PEMBAHASAN}

Kegiatan pengabdian masyarakat ini dilaksanakan dalam bentuk penyuluhan tentang pemanfaatan tanaman keladi hias dalam menambah penghasilan rumah tangga. Ibu rumah tangga di desa Tanjung Gunung Kabupaten Langkat yang tidak bekerja merupakan peserta pada kegiatan pengabdian kepada masyarakat. Berikut ini adalah gambaran umum para peserta penyuluhan "Pemanfaatan Tanaman Keladi Hias Dalam Menambah Penghasilan Rumah Tangga", yang keseluruhan berjenis kelamin perempuan.

Dari informasi yang diperoleh bahwa peserta penyuluhan berpendidikan SMA/Sederajat sebanyak 6 orang $(22,2 \%)$, berpendidikan SMP sebanyak 9 orang $(33,3 \%)$, Pendidikan SD sebanyak 7 orang $(26 \%)$, dan yang tidak Sekolah sebanyak 5 orang $(18,5 \%)$. Tentunya hal ini akan mempengaruhi pola pikir dan perilaku seseorang dalam meningkatkan penghasilan rumah tangga.

Harapan dari pemberian penyuluhan ini adalah para peserta dapat meningkatkan pengetahuan agar memiliki daya kreativitas dan inovatif dalam pemanfaatan tanaman keladi hias untuk menambah penghasilan rumah tangga.

Sebelum pelaksanaan penyuluhan peserta yang memiliki pengetahuan tentang pemanfaatan tanaman keladi hias sebanyak 11 orang $(40,7 \%)$, sedangkan setelah penyuluhan dilaksanakan peserta yang mengetahui tentang pemanfaatan keladi hias dalam meningkatkan penghasilan rumah tangga sebanyak 23 orang (85\%).

Dalam memilih keladi hias calon konsumen akan melihat penampilan dari tanaman tersebut, seperti besar kecil tanaman, warna daunnya, kesegarannya dan kualitasnya. Untuk mendapatkan hal tersebut kita tidak bisa lepas dari peran ilmu pengetahuan, teknologi, dan seni.

Agar tanaman keladi hias memenuhi harapan calon konsumen ada beberapa hal yang harus diperhatikan, antara lain : a). Agar keladi hias bisa tumbuh lebih baik dan subur diperlukan pupuk terbaik, diantaranya pupuk kompos, pupuk gandasil, pupuk dekastar, pupuk vitamin B1, dan pupuk growmore; b). Pengembangbiakan keladi hias dilakukan dengan cara vegetatif dan generatif. Pengembangbiakan secara vegetatif dilakukan dengan cara membelah umbi atau memisahkan

\section{Jurnal Deputi \\ Derma Pengabdian Dosen Perguruan Tinggi}


anakan, anakan yang dipisahkan minimal memiliki dua lembar daun, pemisahan anakan hendaknya dilakukan saat tinggi tanaman 5-10 $\mathrm{cm}$ sebab jika lebih tinggi dari ukuran tersebut tanaman akan stres yang menyebabkan daun dan tangkai menjadi layu. Pengembangbiakan secara generatif dilakukan dengan mengawinkan benang sari dan putik bunga, tujuannya untuk memperoleh keladi hias dengan jenis dan sifat yang lebih baik atau lebih menarik dari induknya; c). Keadaan Iklim, umumnya keladi hias ditanam di lingkungan yang cukup mendapat sinar matahari; $d$ ). Media tanam, media tanam keladi hias yang baik berasal dari campuran kompos dan pasir yang kasar dengan perbandingan 2:1, boleh juga menggunakan sekam padi. Jika menggunakan campuran kompos, pasir kasar dan sekam padi maka perbandingannya $1: 1: 1$, untuk mencegah agar umbi tidak busuk kondisi media tanam jangan sampai becek (Kadir dan Triwahyuni, 2006)

Dalam meningkatkan nilai tambah tanaman keladi hias melalui ilmu pengetahuan, teknologi, dan seni kita dituntut untuk kreatif dan inovatif. Kreatif dan inovatif merupakan jantung rahasia dari sebuah usaha. Seorang pengusaha yang berhasil dan sukses karena mampu berpikir kreatif dan inovatif. Hakekat dari seorang pengusaha kemampuan berpikir dan melakukan tindakan inovasi sesuatu yang baru dan berbeda. Ide yang kreatif dan inovatif menjadi kekuatan penting dalam meluncurkan usaha tanaman keladi hias.

Agar menjadi pengusaha yang berpikir kreatif dan inovatif, ada beberapa persyaratan yang harus dimiliki : a). Pendidikan formal dan non formal mengenai kewirausahaan; b).Kumpulkan sebanyak mungkin ide; c). Menggabungkan ide-ide yang sudah ada sehingga muncul ide baru; d). Memahami permasalahan secara mendalam; e). Memilih yang terbaik dari segi studi kelayakan bisnis seperti dari segi biaya, hukum, teknologi, dan sebagainya (Echdar, 2013).

\section{SIMPULAN}

Kesimpulan dalam pelaksanaan kegiatan pengabdian kepada masyarakat ini adalah sebagai berikut : Ibu rumah tangga desa Tanjung Gunung Kecamatan Sei Bingei Kabupaten Langkat sebagian besar memiliki pendidikan menengah. Pengetahuan ibu rumah tangga yang tidak bekerja dalam berpikir kreatif dan inovatif pemanfaatan keladi hias untuk menambah penghasilan sebelum pelaksanaan penyuluhan masih rendah. Sedangkan setelah pelaksanaan penyuluhan hampir seluruh ibu rumah tersebut memahami program ini.

\section{DAFTAR PUSTAKA}

Anonimus. I. 2012. Kajian Nilai Tambah Produk Pertanian Kementerian Keuangan Republik Indonesia Badan Kebijakan Fiskal Pusat Kebijakan Ekonomi Makro. Jakarta.

Echdhar, Saban.2013. Manajemen Enterpreneurship-Kiat Sukses Menjadi Wirausaha. Jakarta. Cv. Andi Offset.

Kadir, Abdul. 2009. Caladium. Yogyakarta. Penerbit Andi.

Kadir, Abdul dan Terra Ch, Triwahyuni. 2006. Keladi dan Alokasia Hias. Jakarta. Penebar Swadaya.

Kurniawan, A, N. P. S. Asih, Yusammi, . P. C. Boyce. 2013. Studies On The Aeracea of The Lesser Recard For Alocasia Alba. Garden's Bulletin Singgapore 65 (2).

Tomasouw, Ino. 2006. Menanam dan Merawat Keladi Hias. Jakarta. PT. Agromedia Pustaka. 